To appear in R. Truswell (ed.): Oxford Handbook on Event Structure. Oxford University Press, Oxford.

\title{
Nominals and Event Structure
}

\author{
Friederike Moltman
}

CNRS-IHPST and NYU

Final version

\section{Events, verbs, and deverbal nominalizations}

Events have come to play an important role in natural language semantics. While events have been taken to be involved in a wide range of constructions, they most obviously play a role as referents of nominalizations of verbs. It is generally taken for granted that the very same events that verbs describe may act as the referents of NPs with a corresponding deverbal nominalization as head. Thus the very same events described by the sentences in (1a), (2a), and (3a) appear to be what the nominalizations in (1b), (2b) and (3b) stand for:

(1) a. John laughed.

b. John's laughter.

(2) a. John jumped.

b. John's jump

(3) a. John walked.

b. John's walk

That the same event is described by the sentence and referred to by the nominalization appears to be supported by the semantic behavior of predicates. In general, it appears, the same predicates can act as adverbials modifying the verb and as predicates predicated of what the nominalization stands for and moreover as adjectival modifiers of the nominalization: 
(4) a. John laughed intensely.

b. John's laughter was intense.

c. John's intense laughter

(5) a. John jumped quickly.

b. John's jump was quick.

c. John's quick jump

(6) a. John walked slowly.

b. John's walk was slow.

c. John's slow walk

The semantics of nominalizations is closely related to the semantics of adverbial modification, and that needs to be accounted for by any semantic analysis of nominalization based on the semantics of the corresponding verb or sentence.

The main question concerning nominalizations and events then is, how does the semantics of deverbal nominalizations relate to the semantics of the verb or the corresponding sentence? That is, how do deverbal nominalizations obtain their referent, given the semantics of the verb, its complements, and its modifiers? I will discuss three approaches to the semantics of event nominalizations (and the related issue of the semantics of adverbials):

[1] the Davidsonian account

[2] the Kimian (or pleonastic) account

[3] the truthmaker account.

I will conclude that a combination of the three accounts may be required for the semantics of the full range of event and state nominalizations. In addition, I will present data regarding a distinction between two sorts of event nominalizations for psychological and illocutionary verbs that challenge the received view of the identity of the events described by verbs and by (non-gerundive) deverbal nominalizations, namely a distinction between 'actions' and 'products' introduced by the Polish philosopher Twardowski (1911).

\section{The Davidsonian account of event nominalizations}

Clearly the most influential semantic account of events described by verbs and their nominalizations is Davidson's (1967) account, further developed by Higginbotham (1985, 
2000). ${ }^{1}$ According to the Davidsonian account, events act as implicit arguments of verbs and adverbials are predicates of the implicit event argument of the verb. A sentence like (7a) then has the logical form in (7b), with existential quantification over events that are to occupy what can be called the implicit Davidsonian argument position:

(7) a. John walked slowly.

b. $\exists$ e(slowly(e) \& walk(e, John))

The main argument Davidson gives for events acting as implicit arguments of verbs and adverbials as predicates of such events is the possibility of adverb-dropping, that is, the validity of an inference from (7a) to (7c):

(7) c. John walked.

Landman (2000) adds another argument for the Davidsonian view and that is the possibility of permuting adverbial modifiers, as in the valid inference below:

(8) John walked slowly with a stick.

John walked with a stick slowly.

The semantic status of events as implicit arguments of verbs goes along with a particular view about the ontology of events, on which events are primitive entities not to be defined in terms of objects, properties and times (cf. Davidson 1968). Thus, for Davidson, different properties can be used to describe one and the same event and thus won't be eventconstitutive. One and the same event can be described as the rotation of the wheel or as the wheel getting hot, just as one and the same events can be described in both physicalist and psychological terms. Given this view, events could not be conceived as entities strictly dependent on a description, say the content associated with a verb and its arguments. However, conversely, if events are conceived as strictly dependent on objects, properties and times or the content of the verb and its arguments this is still compatible with a Davidsonian view of events as implicit arguments of verbs. In fact, this is Maienborn's (2007) view of

\footnotetext{
${ }^{1}$ For further developments of the Davidsonian event semantics, see Parsons (1990), Moltmann (1997), Landmann (2000).
} 
'Kimian' or abstract states, which she considers implicit arguments of stative verbs (Section $6)$.

Given the Davidsonian event semantics, NPs with deverbal nominalizations such as John's walk will simply pick up the implicit event argument of the verb as the referent (cf. Higginbotham 1985, 2000):

(9) $[$ John's walk] = 1e[walk(e, John) $]$

On this account, the implicit event argument of the verb is the very same as the event described by the event nominalization. The formation of the event nominalization thus goes along with a shift in argument structure: the Davidsonian event argument of the verb will become the external argument position of the nominalization, that is, the argument position that will provide a referent for the entire NP of which the nominalization is the head.

The Davidsonian account immediately explains why the same expressions that act as adverbials generally appear to be able to act predicates or adjectival modifiers of a nominalization of the verb. In all three cases, on the Davidsonian account, the expression is predicated of the very same events.

The Davidsonian account furthermore benefits from a generality of application, allowing a rather straightforward extension to adjectives, though, on my view requiring an enrichment of the ontology so as to include tropes (particularized properties) besides events (Moltmann 2007, 2009, 2013a). Tropes are concrete manifestations of properties in objects, that is, they are properties as particulars, dependent on a particular object as their bearers, rather than properties as universals.

It is a general fact that adjectives, to an extent, exhibit the very same alternation of expressions acting as modifiers of the adjective as well as predicates (or adjectival modifiers) of the adjective nominalization. Thus the modifiers of happy in (10a) and pale in (10b) act as predicates of what the nominalizations happiness in (11a) and paleness in (11b) stand for:

(10) a. Mary is visibly / profound happy.

b. Mary is extremely / frighteningly / shockingly pale.

(11) a. Mary's happiness is visible / profound.

b. Mary's paleness is extreme / frightening / shocking. 
In the case of adjectives, the implicit arguments should be tropes or particularized properties, rather than events (Moltmann 2009, 2013a). ${ }^{2}$ That goes along with the view that nominalizations of the sort of Mary's happiness and Mary's paleness stand for tropes, not events or states. That is, Mary's happiness stands for the particular way happiness manifest itself in Mary and Mary's paleness for the particular manifestation of paleness in Mary. This is the standard view found throughout the literature on tropes, for example in Williams (1953), Campbell (1990), and Lowe (2006). In fact, the view goes back to Aristotle and was common throughout the Aristotelian tradition in medieval and early modern philosophy (way before events gained proper recognition as an ontological category). Why should the implicit argument of an adjective be a trope, rather than an event, or perhaps more specifically a state? That is because a state, as the sort of entity a gerund would stand for, would not have the right properties. For example, 'Mary's being happy' cannot not be profound and 'Mary's being pale' cannot be extreme (Moltmann 2009, 2013a).

Formally this then means that (10a) will have the logical form in (12a), with existential quantification over tropes filling in the 'Davidsonian' argument position of happy, and (10b) will have the logical form in (12b), where Mary's happiness is taken to stand for the maximal trope of happiness of Mary.:

(12) a. $\exists$ e(happy(e, Mary), \& visibly(e))

b. visible(max e[happiness(e, Mary)])

Despite these apparent advantages, the Davidsonian account has also been subject to criticism. A general uneasiness with the account concerns the intuition that events generally should play a role as objects in the semantic structure of sentences only in the presence of nominalizations: as derived objects introduced by nominalizations. ${ }^{3}$ Positing entities as implicit arguments of all verbs constitutes, on that view, an unnecessary proliferation of entities in the semantic structure of sentences. There are in fact two accounts of event nominalizations that would give justice to that intuition: the Kimian account and the truthmaker account. Let us therefore explore those approaches for the semantics of event nominalizations as well as the related issue of the semantics of adverbials. We will see that

\footnotetext{
${ }^{2}$ For the notion of a trope in contemporary metaphysics see, for example, Williams (1973), Campbell (1990), Lowe (2006), as well as Moltmann (2013a, Chap. 2).

${ }^{3}$ Of course setting aside underived event nouns such as fire, war, act, and event.
} 
the truthmaker account meets further challenges for the Davidsonian account, namely regarding more complex adverbial constructions.

\section{The Kimian account of event nominalizations}

The Kimian account of event nominalizations is based on the view that events are introduced into the semantic structure of a sentence generally only by the means of nominalizations. This goes along with Kim's (1976) conception of events, according to which events strictly depend on an individual, a property, and a time, and are introduced as entities by a form of Fregean abstraction. This conception is closely related to the notion of a pleonastic entity of Schiffer (1996, 2003) (which Schiffer (2003) also means to apply to events). Kim's (1976) original account is a rather simply elaboration of the view, and it has subsequently been adopted and further developed by Bennett (1988), Lombard (1986), and others. ${ }^{4}$

Kim's (1976) conception of events consists in the following statement of existence and identity conditions for an event dependent on an object, property, and time, where $[\mathrm{d}, \mathrm{P}, \mathrm{t}]$ is the event dependent on an object $\mathrm{d}$, a property $\mathrm{P}$, and a time $\mathrm{t}$ :

(13) For individuals d, d', properties P, P', and times t, t',

[1] [d, P, t] exists iff $\mathrm{P}$ holds of $\mathrm{d}$ at $\mathrm{t}$.

$[2][d, P, t]=\left[d^{\prime}, P^{\prime}, t^{\prime}\right]$ iff $d=d^{\prime}, P=P^{\prime}, t=t^{\prime}$.

The semantics of event nominalizations then appears straightforward, as below, where the denotation of walk, [walk], is taken to be the one-place property of walking:

(14) $[$ John's walk $]=\mathrm{\imath e}[\mathrm{e}=[\mathrm{John},[$ walk $], \mathrm{t}]]$

Events need not strictly be constituted by the entire content of the event description. Kim (1976) in fact draws a distinction between event-characterizing and event-constitutive properties. Event-characterizing properties are merely properties holding of an event constituted on the basis of another, event-constitutive property. If slow is event-

\footnotetext{
${ }^{4}$ The view of events as derived objects has been more popular among philosophers than linguists, with the exception of Chierchia (1984). Linguists generally adhere to the Davidsonian account.
} 
characterizing, (15a) has the analysis in (15b); but if slow is event-constitutive, (15a) has the analysis in (15c):

(15) a. John's slow walk

b. $\mathrm{e}[\mathrm{e}=[\mathrm{John},[$ walk $], \mathrm{t}]] \& \operatorname{slow}([\mathrm{John},[$ walk $], \mathrm{t}])]$

c. [John, [slowly walk], t]]

The availability of event-characterizing properties conveyed by an event description distinguishes descriptions of events from explicit fact descriptions of the sort the fact that $\mathrm{S}$. Whereas adjective modifiers of event nominalizations may just be event-characterizing, all of the content of $\mathrm{S}$ in a fact description of the sort the fact that $\mathrm{S}$ must be fact-constitutive. This manifests itself in the contrast between (16a), which can be true, and (16b), which can't:

(16) a. John's slow walk was John's walk.

b. The fact that John walked slowly is the fact that John walked.

Events are relatively independent of the description used to refer to them. Facts, by contrast, are entirely reflected in the meaning of explicit fact-referring terms of the sort the fact that $\mathrm{S} .{ }^{5}$

Kim's account does not explicitly define events in terms of a property, an object, and a time. Rather it gives an implicit definition of events, stating their existence and identity conditions in terms of an object, a property, and a time. In particular, events are not taken to be composed in some way of properties, objects, and times. Kim's account in fact introduces events by a form of Fregean abstraction (Frege 1884, Dummett 1973, Hale 1987, Wright 1983). Frege's abstraction principle, given below, just gives identity conditions for objects obtained by the abstraction function $g$ from entities o and o' that stand in some equivalence relation R:

(17) For an equivalence relation $\mathrm{R}, \mathrm{g}(\mathrm{o})=\mathrm{g}\left(\mathrm{o}^{\prime}\right) \leftrightarrow \mathrm{R}\left(\mathrm{o}, \mathrm{o}^{\prime}\right)$.

Thus, Frege introduces directions as entities obtained by abstraction from parallel lines, and

\footnotetext{
${ }^{5}$ For further linguistic support for that view and a semantics for the fact that S, see Moltmann (2013a, Chapt 6). This is the notion of a non-worldy fact, defended by Strawson (1950), as opposed to the notion of a worldly fact, defended by Austin (1979).
} 
natural numbers as entities obtained by abstraction from concepts whose extensions stand in a one-to-one correspondence. (17) can naturally be generalized to n-place abstraction functions applying to $n$ objects that stand in respective equivalence relations to each other. Kim's account of events then introduces events by a three-place abstraction function applying to objects, properties, and times on the basis of the equivalence relation of identity.

An object introduced by Fregean abstraction has just those properties specified by the method of introduction. Thus, given (13), events have identity conditions and existence conditions relative to a time, but they won't have other intrinsic properties. They may, though, act as objects of mental attitudes. This means in particular that events won't have a part structure, won't have a spatial location, won't enter causal relations, won't act as objects of perception, and won't have properties of intensity or other measurable properties. This of course is highly counterintuitive. It is certainly part of our notion of an event for an event to have those properties. By contrast, it is part of our notion of a (non-worldly) fact to lack those properties. This difference between events and facts is also linguistically reflected, in the applicability of the relevant predicates: ${ }^{6}$

(18) a. Mary noticed part of the event.

b. ??? Mary noticed part of the fact.

(19) a. The meeting was in the room.

b. ??? The fact that they met was in the room.

(20) a. John's jump caused the table to break.

b. ??? The fact that John jumped caused the table to break.

(21) a. John saw Bill's jump.

b. ??? John saw the fact that Bill jumped.

(22) a. John's jump was high.

b. ??? The fact that John jumped was high.

(23) a. John's laughter was intense.

b. ??? The fact that John laughed was intense.

Another interesting difference between facts and events is that facts unlike events do not allow predicates of description:

\footnotetext{
${ }^{6}$ See Vendler (1967), Peterson (1997), and Asher (1993) for similar observations.
} 
(24) a. Mary described John laughter / John's jump.

b. ?? John described the fact that John laughed / the fact that John jumped.

The reason for this particular difference appears to be that facts are tied to canonical factdescriptions, but events are not tied to canonical event descriptions. Canonical fact descriptions are of the form the fact that $\mathrm{S}$, descriptions that fully display the nature of a fact and whose content is entirely fact-constitutive. Events do not come with canonical event descriptions, but rather with descriptions that generally do not provide all of the eventconstitutive properties or that contain event-characterizing rather than event constitutive parts. Predicates of description in general require that the term used for the object described won't specify precisely the properties mentioned in the act of describing. The condition is fulfilled in $(25 \mathrm{a})$, but not in $(25 \mathrm{~b})$ :

(25) a. John described the object: he said it was a book.

b. ??? John described the book: he said it was a book.

The difference in description (that facts are tied to canonical descriptions, but not events) may explain the applicability of verbs of description. But it cannot be considered the feature distinguishing facts and events, as Bennett (1988) did. The difference in description won't account of the other differences in properties between events and facts. The distinction between events and facts is clearly an ontological one, not one residing in their description.

The main objection to Kim's account of events has been that it assimilates events to facts. Note that any property, however unspecific or logically complex, can, for Kim, be eventconstitutive. Any predicate expressing a non-natural or indeterminate property, any explicitly or implicitly quantified predicate, and any negated or disjunctive predicate can, on Kim's account, individuate an event (together with an individual and a time). But this is characteristic of facts, not events. Non-specific properties, negation, disjunction, and quantification can be fact-constitutive, but generally not event-constitutive. That is because events as concrete objects must be maximally specific or at least grounded in specific properties. It is the groundedness of events that distinguish events from facts (Moltmann 2007). ${ }^{7}$ Part of that is also that events unlike facts need to involve particular participants; a

\footnotetext{
${ }^{7}$ The notion of a specific property that I am using is closely related to Armstrong's (1978) notion of a 'natural property' and Lewis (1983) notion of a 'non-redundant- property.
} 
quantifier or disjunction does not suffice for their individuation. This is clearly part of our notions of event and fact. Take the property of making several mistakes (separately) and the property of eating an apple or a pear:

(26) a. John made several mistakes.

b. John ate an apple or a pear.

Then (26a) describes several events, all the events involving a particular mistake, but only one fact, the fact that John made several mistakes. (26b) describe an event that involves either an apple or a pear, but it will describe a fact not involving one particular fruit, but constituted by a disjunction, namely the fact that John ate an apple or a pear

Given the Kimian conception of events, one might try to account for the groundedness of events by imposing the restriction that events can be constituted only by fully determinate properties. More adequately, since events generally involve change, events might be conceived as transitions from an object having one determinate property at a time $t$ to the object's having a contrary determinate property at a subsequent time t' ( Lombard 1986). More complex events may then be built from such transitions, either as collections of transitions or as a transitions viewed with a particular, possibly complex property as its gloss, as would be the case with events for which a totality condition is constitutive (Section 3). But if events are introduced by abstraction, even if based on such specific property changes, they will still lack the typical event properties, since the only properties they can have are those stipulated by the strategy of their introduction. Making events be dependent on specific properties will make no difference to the properties events have if events are still introduced by abstraction.

Moreover, such a more complex conception of events poses a problem for the Kimian account of event nominalizations. Most verbs in English do not describe the kinds of transitions that could constitute or ground events. In fact, it is hard to find any reasonably simple predicates at all that do. Even such predicates as become soft or turn red, which express a simple property change still involve a non-specific property. Given the range of verbs that can describe events, there are at least five major classes of verbs whose content merely characterizes an event, but would not be fully constitutive of it:

[1] verbs involving quantification over kinds of properties: change

[2] verbs expressing quantification over spatial positions: move towards, walk

[3] verbs expressing quantification over types of actions having a particular of causal effect: disturb, kill 
[4] verbs expressing quantification over types of actions and expressing just a mode of action, such as hurry, obey, and continue

If events are 'introduced' into the semantic structure of sentences only by nominalizations, then the descriptive content of a nominalization of any of the verbs just mentioned would not be event-constitutive. It would underspecify the event that is to be introduced. For example, John's change has a descriptive content that underspecifies the particular event of change that is being referred to. The same holds for John's walk toward the house (which leaves open what changes in spatial positions exactly took place), John's disturbance of Mary (which leaves open what exactly John did to cause Mary's state of irritation), and John's hurry (which leaves out what exactly John did that was done in a hurried way). Deverbal nominalizations cannot generally introduce an event by providing its constitutive properties. They can at best give a partial characterization of an event, leading to a description that would merely serve to

pick out one event rather than another. This is why the Kimian conception of events cannot provide a semantics of event nominalizations.

The Kimian account must go along with a different analysis of adverbials since adverbial modifiers can no longer be considered predicates of the implicit event argument of the verb. Temporal and spatial adverbials could alternatively be treated as operators whose semantics will involve quantification over spaces or times acting as indices of evaluation (cf. Cresswell $1985)$, as in (27b) for (27a), where then is represented by a suitable operator THEN:

(27) a. John was happy then.

b. THEN(happy(John))

Adverbials could also be treated as predicate modifiers (cf. Reichenbach 1947), as below:

(28) a. John walked slowly

b. $(\operatorname{slowly}($ walk $))($ John $)$

The validity of adverb-dropping could then be ensured by imposing general conditions on at least certain kinds of predicate modifiers. One issue for this account is that it would not assign the same meaning to expressions when they act as adverbials and as adjectives $($ slowly - slow). The account could only assign related meanings to the two uses of slow(ly), roughly as follows. Slow holds of an event $e$ if the changes constitutive of $e$ have a more than average distance from each other, and slowly $\mathrm{P}$ holds of an entity $d$ iff the changes $P$ attributes 
to $d$ have a more than average distance from each other. More difficult to handle on this account, though, would be the possibility of modifier permutation (as pointed out by Landman 2000).

We can overall conclude that the Kimian account fails for event nominalization, first because it is based on an untenable ontological view of events (blurring the distinction between facts and events) and second because it would be inapplicable to actual event nominalizations in natural language. In addition, it requires a more complicated semantics of expressions that can function both as adverbials and as event predicates.

\section{The truthmaker account of event nominalizations}

Another way for nominalizations to introduce events as 'new objects' into the semantic structure of a sentence is as truthmakers, an approach pursued in Moltmann (2007). In what follows, I will outline a truthmaker account of nominalizations as well as of adverbial constructions and mention some critical issues for the approach.

A truthmaker is an entity in virtue of which a sentence is true. The truthmaking idea, that sentences are true in virtue of some entity in the world, though not uncontroversial, has been pursued by a number of philosophers, including Armstrong (1997, 2004, Rodriguez-Pereira 2005, Restall 1996, Mulligan/Simons/Smith 1984, Fine 2012, 2014, to appear). ${ }^{8}$ The standard motivation for the truthmaking idea is the view that the truth of a sentence must be grounded, and that it must be grounded in an entity in the world. The more recent approach to truthmaking, Fine's (2012, 2014, to appear) Truthmaker Semantics, has a somewhat different motivation. Rather than being concerned with the grounding of truth, it is simple based on the view that for each sentence $S$ there is a set of (possible or actual) entities that are wholly relevant for the truth of $S$, that is, that are exact truthmakers (or verifiers) of $\mathrm{S}$. In addition, on Fine's view, there is a set of entities that are wholly relevant for the falsity of $S$, the

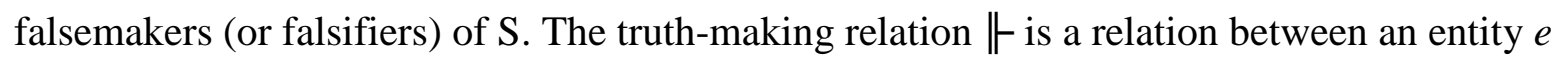
and a sentence $S$. Thus 'e $\Vdash S$ ' means ' $S$ is true in virtue of e'. While truthmaking is at the center of many contemporary metaphysical discussions, it is generally not used for the semantic analysis of natural language, except in the recent version of Fine (2012, 2014, to

\footnotetext{
${ }^{8}$ See also the contributions in Beebee/Dodd (eds.) (2005).
} 
appear) and in the exploration of truth-making for the semantics of nominalizations in Moltmann (2007).

On the standard truthmaking view, truthmakers are actual entities as part of the actual world. The recent approach to truthmaking by Fine (2012, 2014, to appear) allows them to be merely possible entities. Some philosophers such as Russell and Armstrong take truthmakers to be states of affairs, while Fine calls them 'states'. Others such as Mulligan / Simons / Smith (1984), take truthmakers to be events as well as tropes and perhaps individuals. Yet others stay neutral as regards the nature of truthmakers (Rodriguez-Pereyra 2005).

If events are truthmakers of sentences, then the semantics of nominalizations may make use of the truthmaking relation to establish as their referent an event that would not have been part of the semantic structure of the sentence without the nominalization. Thus, the semantics of John's walk, in first approximation, would be as below:

(29) $[$ John's walk] = e e[e $\Vdash J o h n$ walks $]$

That is, John's walk refers to the unique event that makes the sentence John walks true.

The truthmaking relation then should not only be involved in the semantics of nominalizations, but also that of adverbials. Adverbials on the truthmaker account will be considered constructions triggering the introduction of truthmakers (Moltmann 2007). For that purpose, the truthmaking relation needs to be viewed not only as a relation between entities and sentences, but also as a relation applying to entities and pairs consisting of a property and an object or more generally an n-place relation and $\mathrm{n}$ objects, that is, simple structured propositions. A simple structured proposition $\langle\mathrm{P}, \mathrm{o}\rangle$ with a property $\mathrm{P}$ and an object $\mathrm{o}$ is considered true (in a circumstance c) just in case P (in c) holds of o (in c), and as a truthbearer will also have truthmakers, just like sentences. The truthmaking conditions of (30a) will thus involve the truthmaking relation applying to an event $e$ and a pair consisting of the property

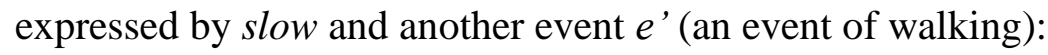

(30) a. John walked slowly.

b. e $\Vdash$ John walked slowly iff there is an event e', e' $\Vdash$ John walked \& e $\Vdash<$ slow $]$, e’>

(30a) involves two truthmakers: an event e making the unmodified sentence true and another entity e' making the predication of the adverbial of e true. e in some way includes e', since a 
truthmaker generally includes the entities that the sentence or proposition that it makes true is about. This obviously need not be made part of the semantics of adverbially modified sentences.

Crucially, on this analysis, the simple sentences John walks won't involve events in its semantic structure, and thus the truthmaker account allows events not to be implicit arguments of verbs yet takes them to be what adverbials are predicated of. Using truthmaking for the semantics of adverbials has further advantages over the Davidsonian account regarding stacked adverbials and the interaction of adverbials with quantifiers, as we will see.

There are two different views about how 'big' the truth maker for a sentence may be. While many assume truth making to satisfy Monotonicity (if e $<\mathrm{e}^{\prime}$ and e $\Vdash S$, then $\mathrm{e}^{\prime} \Vdash \mathrm{S}$ ), others hold the view that a truthmaker should strictly consist only of features in virtue of which a sentence is true, that is, it should be an exact truthmaker (Rodriguez-Pereyra (2000), Moltmann (2007), Fine (2012, 2014, to appear). Thus, for example, the sentence John walks is made true by a walking event of John, but not by an event that is a walking and yawning of John or an event that is a walking of John and Mary. This notion of an exact truth maker is obviously what is needed for the semantics of nominalizations as well as adverbial modification.

The truthmaker approach would be equally applicable to adjective nominalizations and modifiers of adjectives. Thus, John's happiness would have the semantics in (31) the sentence (32a) the semantics in (32b) -- in first approximation: ${ }^{9}$

(31) [John's happiness] = $\mathrm{e}[\mathrm{e} \Vdash$ John is happy]

(32) a. John is profoundly happy.

b. $\exists \mathrm{t}(\mathrm{t} \Vdash$ John is happy \& profound $(\mathrm{t}))$

The truthmaker that makes the sentence John is happy true is a trope that instantiates happiness in John. Such a trope is what profoundly applies to and John's happiness refers to.

\footnotetext{
${ }^{9}$ Note, though, that modifiers of adjectives do not always alternate with adjectival modifiers of the corresponding nominalization (Moltmann 2007):

(i) a. John is highly talented

b. ??? John's talent is high,

(ii) a. John's talent is great.

b. ??? John is greatly talented).
} 
The view that event and trope nominalizations stand for the truthmakers of the sentences that correspond to them requires some further elaboration. First, the analysis in (31) is not compositional: it makes the semantics of a noun dependent on the syntactic context in which the noun occurs (that is, dependent on which complements it takes). In addition, the analysis would be inapplicable to quantificational NPs with nominalizations, as below:

\section{(33) a. every walk John took \\ b. every walk anyone every took}

The truthmaker semantics of nominalizations thus should better assign an extension to the nominalizations on the basis of an argument of the verb, as below:

(34) $\left[\right.$ walk $\left._{\mathrm{N}}\right]=\left\{\langle\mathrm{e}, \mathrm{d}\rangle \mid \mathrm{e} \|<\left[\right.\right.$ walk $\left.\left.\left._{\mathrm{V}}\right], \mathrm{d}\right\rangle\right\}$

The semantics of event nominalizations in (29) cannot be right also because there are many events that would be exact truthmakers of John walked: a maximally continuous walk as well as smaller parts of it. John's walk can refer only to the maximally continuous walk. This temporal maximality condition is not tied to the definiteness of John's walk because it also is associated with quantificational NPs as in $(33 \mathrm{a}, \mathrm{b})$. But the condition is not associated with the gerund John's walking: John's, which does not necessarily refer to the temporally maximal event (as one can say 'John's walking from 9 to 10 am was the reason that he missed the meeting -- in fact John walked from 10 to 11'). This means that it could not be a condition on the individuation of events in general or a condition on reference to truthmakers. What appears to be at stake rather is the mass-count distinction. Walking is a mass noun (too much walking, not too many walkings), whereas walk is a count noun (many walks). Count nouns generally describe countable events, events that have some form of integrity. Achievements and accomplishments such as John's jump and the destruction of the palace are inherently countable. But with activity and stative verbs, the events referred to are not inherently delimited, which is why the nominalization, if it is a count noun, will impose the condition that the event be a maximal temporally continuous event. ${ }^{39}$ The semantics of activity 
nominalizations should thus be as in (35) (with $<_{\mathrm{t}}$ being the temporal part relation among events): ${ }^{10}$

(35) $[$ walk $]=\left\{\langle\mathrm{e}, \mathrm{d}\rangle \mid \mathrm{e}=\max _{<\mathrm{t}}\left(\left\{\mathrm{e}^{\prime} \mid \mathrm{e}^{\prime} \Vdash<[\right.\right.\right.$ walk $\left.\left.\left.\left.], \mathrm{d}>\right\}\right)\right)\right\}$

The truthmaker approach appears particularly suited for the analysis of adverbial modification, and it is applicable to a range of cases for which the Davidsonian approach has difficulties.

One potential issue for the Davidsonian account is adverbials that do not act as predicates of the Davidsonian event argument, but rather of what would be a more complex event, an event somehow incorporating the contribution of another adverbial:

(36) a. The ball suddenly rolled quickly.

b. John spoke very slowly with patience.

c. Mary danced slowly very elegantly.

What is sudden according to (36a) is the 'quick rolling event', not the rolling event as such. What was done with patience in (36b) is 'John's speaking slowly', not just John's speaking, and what was done elegantly according to (36c) was Mary's dancing slowly, not just Mary's dancing. Examples such as in (36a-c) also do not allow for modifier permutation.

A Davidsonian has to assume that suddenly in (36a) acts as a predicate of the event argument of the verb. But the event here is not an event of the ball's rolling but of the ball's rolling quickly, and such an event could only be an event argument of quickly, not of roll. This means that the Davidsonian would need to postulate additional event argument places for adverbs as well. As a matter of fact, this is precisely what Peterson (1997) proposes, with the following analysis of (36a):

(37) $\exists e^{\prime} \exists e\left(\operatorname{suddenly}\left(e^{\prime}\right) \&\right.$ quickly(e', e) \& roll(e, the ball))

\footnotetext{
${ }^{10}$ The maximality condition is also associated with nominalizations referring to tropes. John's happiness refers to the trope that is maximal with respect to occupying a continuous stretch of time. Here, because happiness is a mass, not a count noun, the condition is associated with the definiteness of a mass NP (cf. Sharvy 1980).
} 
Thus, quickly expresses a two-place relation between events. The second arguments would be the familiar Davidsonian events, events that are said to be quick -- in (36a) a simple event of the ball's rolling. The first arguments of quickly, however, would be events of the 'quickness' of events acting as the second arguments -- in (36a) the quickness of a rolling. The first arguments of quickly should in fact better be viewed not as events, but as tropes, namely tropes that take events as bearers that would be the second arguments of quickly. That is, they are the particular manifestation of quickness, in events, such as the quickness of the event of the ball's rolling. (37) then states that there is an event e that is a rolling of the ball and is quick and moreover that there is a trope that is e's quickness and is sudden. ${ }^{11}$

The Davidsonian account of stacked adverbials needs to posit the very same argument structure for adverbials as it would for the corresponding deadjectival nominalizations, making use of tropes as implicit arguments of adverbials. Stacked adverbials thus are not a serious challenge for the Davidsonian, once it is accepted that they require the same ontology and argument structure as de-adjectival nominalizations do.

Stacked adverbials, however, also receive a straightforward analysis within the truthmaker account, permitting a simpler argument structure of verbs as well adverbial modifiers. On that analysis, an adverbial will act as a predicate of the truthmaker of a sentence modified by another adverbial. Thus (36a) will have the truthmaking conditions below:

$$
\begin{aligned}
& \Vdash \text { The ball suddenly rolled quickly iff } \exists \mathrm{e}^{\prime} \exists \mathrm{e}^{\prime \prime} \text { (e } \Vdash<\text { [suddenly], e'> \& } \\
& \mathrm{e}^{\prime} \Vdash<\text { [quickly], e'’> \& e', } \Vdash<\text { [roll], the ball }>\text { ) }
\end{aligned}
$$

According to (38) suddenly in (36a) will be predicated of a trope of an event, namely the quickness of the ball's rolling, whereas quickly, as before, is predicated of the event of the ball's rolling. (36a) in fact involves three truth makers: the event of the ball's rolling (the truthmaker of the proposition that the ball rolled), the trope of the quickness of the ball's rolling (the truth maker of the proposition that the ball rolled quickly), and the trope of the suddenness of the quickness of the ball's rolling (which is the truthmaker for the entire sentence).

\footnotetext{
${ }^{11}$ Suddenly should actually express a two-place relation as well, taking in (36a) a trope e"' of suddenness and a trope e' that is sudden (a quickness trope) as arguments, as below:

(i) $\exists \mathrm{e}^{\prime} \mathrm{e}^{\prime} \exists \mathrm{e}($ suddenly(e'’, e') \& quickly(e', e) \& roll(e, the ball))
} 
Again the truthmaker-based analysis of stacked adverbials reflects the argument structure and ontology of nominalizations on the truthmaker-based account. Given the truthmakerbased account, verbs lack a Davidsonian argument position for events, just as event nominalizations do not come with an external argument position for events. Moreover, adjectives/adverbials will express just one-place properties, lacking an additional, 'Davidsonian' argument position for tropes, just as deadjectival nominalizations will lack an 'external' argument position for tropes on the truthmaker-based analysis.

Stacked adverbials do not present a serious challenge for the Davidsonian account, since their semantics goes along with a trope-based Davidsonian semantics of de-adjectival nominalizations. However, adverbial modifiers with certain logically complex sentences do, as do corresponding nominalizations.

Let us then first address the truthmaking of logically complex sentences as such. The truthmaking conditions of disjunctions and existentially quantified sentences are fairly uncontroversial as below (formulated with substitutional quantification):

(39) a. e $\Vdash$ A v B iff e $\Vdash$ A or e $\Vdash B$

b. e $\Vdash \exists x S$ iff for some substitution instances of $S$ with respect to ' $x$ ', e $\Vdash S$ '

Also the truthmaking condition on conjunctions is straightforward. Adverbial modifiers may apply to conjunctions of verbs or VPs (John quickly came and left). Therefore conjunctions should have as truthmakers the sum of truthmakers of the conjuncts:

(40) e $\Vdash$ S \& S' iff there are entities e, e', and e' such that e $=\operatorname{sum}\left(\left\{\mathrm{e}^{\prime}, \mathrm{e}\right.\right.$ '’ $\left.\}\right)$, and $\mathrm{e}^{\prime} \| \mathrm{S}$ and $\mathrm{e}^{\prime \prime} \| \mathrm{S}^{\prime}$.

More controversial are the truthmaking conditions of universally quantified and negative sentences. As Russell (1918/19), more recently Armstrong (1997, 2004) and Fine (to appear) have argued, universal quantification requires an irreducibly general state for its truth-making, involving the condition that a set be exhaustively included in another. Let me call this the totality condition. A truthmaker of a universally quantified sentences thus cannot be identified with the sum of truthmakers of corresponding atomic sentences. Rather, as Armstrong (1997, 2004), and, similarly, Fine (to appear) propose, it should be an aggregate of the sum of truthmakers of corresponding atomic sentences with the relevant totality condition (to the effect that the entities involved in the 'singular' truthmakers exhaust the actual domain or a relevant quantifier restriction). 
In the context of present interest in the semantics of nominalizations and adverbials, it is easy to see that truthmakers that includes a totality condition are needed for the ooosemantics of adverbial modification of universally quantified sentences. Examples are (41a, b), contrasting with $(42 b, c)$ :

(41) a. John carefully eliminated every mistake.

b. John intentionally mentioned every participant.

(42) a. John eliminated every mistake carefully.

b. John mentioned every participant intentionally.

In (41b), what is said to be careful is John's doing away with the entirety of the mistakes, and in (41b) what is said to be intentional is John's mentioning the entirety of the participants. (41a) and (41b) differ from (42a) and (42b), where carefully and intentionally apply to the individual events instead.

Even nominalizations, it appears, may involve a totality condition as part of their referent, as below on the relevant reading:

(43) a. John's careful elimination of every mistake

b. John's intentional mentioning of every participant

On the relevant reading, in (43a) Joh was careful making sure all mistakes are eliminated, and on the relevant reading of (43b) it was part of John's intention that the participants were exhaustively mentioned.

Armstrong $(1997,2004)$ proposes that the truthmaker for the statement 'All P are Q' is the aggregate consisting of the sum (or aggregate) of the 'singular' states of affairs of the sort 'd's being $\mathrm{P}$ and $\mathrm{Q}^{\prime}$ and the states of affairs that consists in the aggregate of those singular truth makers constituting all states of affairs involving P. Reformulating this condition for events, this means that the following condition would hold for the truth-making of universally quantified sentences, where ALL is the condition that holds between a sum and another sum if the first exhausts the second:

(44) e $\Vdash$ Every A is B iff there are events e' and e' such that e $=\operatorname{sum}\left(\left\{\mathrm{e}^{\prime}, \mathrm{e}\right.\right.$ ' $\left.\}\right)$ and for any substitution instance $\mathrm{S}$ of every $\mathrm{A}$ is $\mathrm{B}$, there is an event $\mathrm{e}$ ", such that $\mathrm{e}$ ", $<\mathrm{e}$ ", and 
$\mathrm{e}^{\prime \prime} \|^{\prime} \mathrm{S}$ and $\mathrm{e}^{\prime}=\operatorname{ALL}\left(\mathrm{e}^{\prime \prime}, \operatorname{sum}\left(\left\{\mathrm{e} \mid \mathrm{e} \Vdash \mathrm{S}^{\prime}\right.\right.\right.$, for some substitution instance $\mathrm{S}^{\prime}$ of every $\mathrm{A}$ is $\mathrm{B}\})$ ).

Note that since totality events are composed of ordinary events and a totality condition, they are distinct from facts as described by the fact that every $\mathrm{A}$ is $\mathrm{B}$, that is, non-worldly facts introduced by an explicit fact description.

Given (44), the truthmaking condition of (41a) will then be as follows:

(45) e $\Vdash$ John carefully eliminated every mistake iff there is an event e' such that:

e $\Vdash<$ carefully], e’> \& e’ $\Vdash$ John eliminated every mistake

Again, it is assumed that in addition to sentences, structured propositions consisting of a property and an object may have truthmakers, that is, in (45) $<$ [carefully], e'>.

Adverbial modification of universally quantified sentences as well as nominalizations in which universal quantification plays an event-constitutive role pose a serious issue for the Davidsonian account of adverbs and nominalizations. In order to treat carefully and intentionally in $(41 \mathrm{a}, \mathrm{b})$ as predicates of events, the Davidsonian would require additional event argument places for quantifiers like every. The exhaustion of a set of entities in certain types of events would be partly constitutive of the event that carefully in (41a) and intentionally in (41b) are predicated of (e.g. in (41a) John was careful in that the mistakes he eliminated constitute all the mistakes). If an event were to be made an additional argument of every, then every would express a three-place relation between events, sets, and sets. (41a) would then have the logical form below:

(46) $\exists \mathrm{e}^{\prime}($ carefully(e') \& every(e', [mistake $\left.],\{\mathrm{x} \mid \exists \mathrm{e}(\mathrm{eliminate}(\mathrm{e}, \mathrm{John}, \mathrm{x})\})\right)$

It would be part of the lexical meaning of every to specify how the event e' relates to the event argument of eliminate: e' must be an event of John's exhausting the mistakes in his eliminations. Of course, it would be highly peculiar if that should be part of the meaning of every. Note that a sentence like every student eliminated every mistake would have to be about two additional events, one being constituted by the exhaustion of the students in acts of elimination and another by the exhaustion of the mistakes in acts of elimination. Furthermore, 
a sentence like every teacher showed every student every mistake would be about three events constituted by an exhaustion of a set.

Another serious problem for the Davidsonian account are adverbial modifiers modifying negated VPs as in the examples below:

(47) a. John intentionally did not get up before $8 \mathrm{am}$.

b. John frequently does not get up before $8 \mathrm{am}$.

As in the case of universal quantification, in order to obtain an entity the adverbial modifier could be predicated of, the Davidsonian account would have to posit an implicit argument position for events, or rather states of not happening, as part of the meaning of negation not. This again is highly implausible, especially since negation is generally treated as a syncategorematic expression, lacking arguments entirely.

It is not entirely straightforward, though, to treat adverbial modification of negated VPs on the truthmaker account. Negation has been considered a problematic issue for the truthmaker idea as such. It has been a matter of controversity whether negative sentences should have truthmakers in the first place and what their truthmakers should be. For present purposes, clearly negative sentences indeed have truthmakers since they permit adverbial modifiers taking scope over the negation. Given the truthmaker account, intentionally in (47a) is predicated of the truthmaker of a negated sentence John did not get up before $8 \mathrm{am}$, and frequently in (47b) acts as a quantifier ranging over truthmakers of the same negated sentence. Thus a truthmaker semantics is needed that assigns truthmakers to negative sentences.

The most straightforward account of the truthmaking of negative sentences has been given recently by Fine $(2012,2014$, to appear). Fine, crucially, makes use not only of the

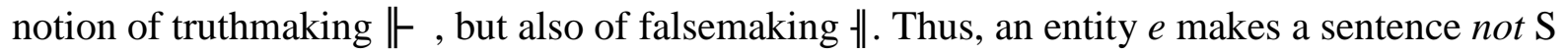
true just in case $e$ makes $S$ false:

(48) e $\Vdash$ not $\mathrm{S}$ iff e $\| \mathrm{S}$

This condition makes truthmakers of negative sentences available without requiring that they meet particular conditions on individuation. Yet as truhmakers they are fully specific and part of the world, unlike non-worldly facts or Kimian states.

The question whether there are 'negative events' as referents of nominalizations has received a significant amount of attention in the literature. There obviously are formal 
constraints on forming negative nominalization requiring non as a morpheme instead of the particle not (as in the often-cited the nonarrival of the boat). This is clearly not part of a productive formation of nominalizations for negative events though. The non-thought, the non-jump, the non-meeting etc are impossible. A more productive way of forming terms for negative events involves the nominalizations of fail and lack, as in John's failure to act and John's lack of understanding. But those terms are associated with particular restrictions on individuating the corresponding negative states or events. John's failure to act presupposes a certain expectation regarding John's acting and John's lack of understanding may similarly presuppose an expectation or standard. There does not seem to be systematic way in English for forming nominalizations standing for the truthmakers of negative sentences. This means that Fine's truthmaking conditions on negative sentences, while providing the truthmakers to which adverbials modifying negated VPs apply, can be at best only part of the conditions involved in the semantics of negative nominalizations.

The use of adverbials with quantifiers and negation indicates that there is in principle no limit as to the 'generation' of 'higher-order events', and this poses a serious problem for the Davidsonian account. At the same time, nominalizations involving quantification or negation appear to be subject to more restrictions, requiring not just truthmaking but further conditions for them to have a referent.

The Davidsonian view of events as implicit arguments of verbs provides an immediate account of event nominalizations. With its straightforward extension to trope nominalizations, the Davidsonian account gives a plausible account of stacked adverbials. The semantics of adverbials involves the very same ontology that the extended Davidsonian view would posit for the semantics of adjectives and their nominalizations anyway.

The alternative, truthmaker account would do away with the Davidsonian argument position of verbs, adjectives, as well as adverbials. While this gives justice to an intuition that the semantics of those expressions is simpler than the Davisonian would have it, there are reasons to in fact not pursue the truthmaker account in that way. Give the relation of exact truthmaking, events, like any other fully individuated entities (including tropes), appear unsuited for the exact truthmaking relation (Moltmann 2013a, Chap. 1). Events generally have more properties than are needed for the exact truthmaking of sentences. Take the sentence John is walking. A concrete event of John's walking has a location, a manner, an intensity, possibly a company, and other features not relevant for the truth of John is walking. That is, events, like tropes and enduring objects, are too thick to serve as exact truthmakers. Thus, 
there is reason not to apply truthmaker semantics to the semantics of nominalizations and simpler adverbial constructions (including stacked adverbials as in (36)).

There are, arguably, entities, though, that we refer to in natural language that serve the exact truthmaker role, namely 'cases', entities we refer to as the case in which John might be walking, the case in which John does not get up before 8, the case in which John eliminates every mistake etc,(Moltmann, to appear b, ms). But 'cases' have very different properties from events. In fact they have a lot fewer properties than events, lacking, generally, a location, a temporal part structure and causal roles (Moltmann, to appear b, ms). Take 'the case in which John does not get up', which would be the exact truthmaker of the sentence John does not get up. That case cannot be located in Germany, does not have temporal parts (if any in fact), and cannot make Mary fall asleep again. That is, it lacks a spatial location, temporal parts and causal roles, unlike events.

Despite the difficulties with a truthmaker-based semantics for nominalizations and simple adverbial modification, the truthmaker-based semantics appears the only option and in fact an entirely appropriate one for adverbial modification of quantified and negated sentences. This means that the Davidsonian semantics of event (and trope) nominalizations as well as simpler adverbial constructions should best be combined with a truthmaker account of more complex constructions involving adverbials and complex nominalizations.

\section{The action-product distinction and the mass-count distinction among verbs and event nominalizations}

There is another challenge for both the Davidsonian and the truthmaker account of event nominalizations and that concerns a distinction between two sorts of event-like mental or illocutionary entities. This is Twardowski's (1911) distinction between actions and products, a distinction that concerns particularly nominalizations of psychological and illocutionary verbs (see Moltmann (2013a, Chap. 4, 2014, to appear a) for a recent discussion and further development of Twardowski's distinction). According to that distinction, nominalizations such as thought, judgment, decision, claim, request, and promise describe non-enduring 'products' of the event described by the verb. By contrast, gerunds such as thinking, judging, deciding, claiming, requesting, and promising describe actions, the very same things described by the corresponding verbs. The non-enduring products of actions are as concrete as the actions and in fact spatio-temporally coincident with them. 
Actions and products differ fundamentally in their properties. Most importantly only products may bear truth or satisfaction conditions, but not actions. This is reflected not only in the applicability of true and false to products but not actions, but also in the applicability of predicates expressing satisfaction conditions of various sorts, such as satisfy, fulfill, implement, execute etc:

(49) a. John's claim / judgment that that $\mathrm{S}$ is true / false.

b. ?? John's claiming / judging that $\mathrm{S}$ is true / false.

c.?? John's action (of claiming / judging) is true.

(50) a. John's request to be promoted was fulfilled.

b. ?? John's requesting / act of requesting was fulfilled.

c. John's decision was implemented.

d. ?? John's act of deciding was implemented.

e. John's command that people leave the building was executed.

f. ?? John's commanding / act (of commanding) was fulfilled.

This also means that products but not actions will be able to enter logical relation (in virtue of their truth or satisfaction conditions). It also means that products but not actions could play the role that propositions play on standard views of attitude reports and sentence meaning (Moltmann 2013a, Chap. 4, 2014, to appear a). Note, though, that the applicability of predicates of satisfaction makes clear that products cannot be identified with propositions (propositions cannot be fulfilled, implemented, or executed). Rather products are entities sui generis, sharing similarities with both propositions and events, but are not to be identified with either of them.

Products differ from actions furthermore in entering relations of exact similarity just on the basis of being the same in content, provided they involve the same force and possibly physical manifestation. This is reflected in the applicability of is the same as, a predicate expressing exact similarity in English:

(51) a. John's thought is the same as Mary's.

b. John's thinking is the same as Mary's.

Whereas the truth of (51a) just requires sharing of content, (51b) appears to require more, say sharing of the particular way of thinking. The presuppositions on exact similarity of products 
are illustrated below, that is, that only products involving the same force and mode of realization can be exactly similar:

(52) ??? John's thought is the same as Mary's remark.

(52) states exact similarity among different sorts of products and thus could not be true at all.

There are further properties that distinguish actions and products. For example, only products not actions have a part structure based on partial content and only products not actions can enter causal relations on the basis of content, that is, only products can have causal effects in virtue of their content (thus only John's claim may cause astonishment or puzzlement in virtue of its content, but not so for John's act of claiming) (Moltmann, 2013a, Chap. 4, Moltmann 2014, to appear).

It is clear then that an ontological distinction must be made between certain types of events and their non-enduring products. These types of events consist of (certain) mental acts as well as illocutionary acts. For the semantics of nominalizations this means that non-gerundive nominalizations of psychological and illocutionary verbs do not just pick up the implicit event argument of the verb. Rather their semantics will be more complex involving a function mapping an implicit event argument onto its non-enduring product. Thus, whereas gerunds have the simple semantics in (53a), product nominalizations will involve a more complex semantics, as in (53b), with prod being a function mapping an event onto its non-enduring product:

(53) a. $[$ claiming $]=\{\langle e, x\rangle \mid\langle e, x\rangle \in[$ claim $]\}$

b. $\left.\left[\operatorname{claim}_{\mathrm{N}}\right]=\left\{<\mathrm{e}^{\prime}, \mathrm{x}>\mid \exists \mathrm{e}(<\mathrm{e}, \mathrm{x}\rangle \in\left[\operatorname{claim}_{\mathrm{V}}\right] \& \mathrm{e}^{\prime}=\operatorname{prod}(\mathrm{e})\right)\right\}$

All non-gerundive nominalizations of psychological and illocutionary verbs appear to be product nominalizations, thus requiring the more complex semantics, given the Davidsonian semantics of events. This raises the question of how general the distinction between actions and products is. Twardowski's (1911) own view was that the action-product distinction includes the distinction between physical actions and their products, for example that between an action of walking and a walk, an act of jumping and a jump, and an act of screaming and a scream. Clearly, an action of walking and a walk and an act of jumping and a jump do not differ in properties in the way an act of judging and a judgment and an act of claiming and a claim do, since a walk and a jump do not have satisfaction conditions or other representation- 
related properties. The same holds for a scream as a byproduct of a state of agitation, in contrast to an act of screaming. Linguistically, though, the same sorts of nominalizations are used for physical products as for cognitive and illocutionary products: jump, scream, and walk are morphologically on a par with belief, claim, and hope.

All nominalizations of the sort of walk, jump, scream, belief, claim, and hope differ from gerunds in one common respect, however, and that is that they are count nouns rather than mass nouns. Count nouns typically apply to entities viewed as integrated wholes, whereas mass nouns apply to entities not viewed as integrated wholes (Moltmann 1997). The count character of walk, jump, and scream manifests itself in that such nouns describe events that are viewed as wholes, which is not the case for gerunds. This difference is reflected in the way evaluative properties apply. If Mary's dance was unusual, it may be so just because of the very beginning and the very end. But if Mary's dancing was unusual, then unusualness must pertain to Mary's dancing throughout the time it lasts. Similarly, amazing when applying to John's scream naturally evaluates John's scream as a whole, whereas when it evaluates John's screaming, it evaluates an activity throughout the time it goes on. Cognitive and illocutionary products are generally described by count nouns (which means they are generally viewed as integrated wholes, say in view of the unity of their representational content), whereas the corresponding actions or states are described by mass nouns when using gerunds. Thus suggests that it is the mass-count distinction that may have mislead Twardowski to posit a distinction between physical actions and physical products as well.

The mass-count distinction of course needs to be taken into account for the semantics of nominalizations. If gerunds and other nominalizations differ with respect to the mass-count distinction, this raises the question of the mass-count distinction among verbs. It appears, given a range of criteria, that verbs always classify as mass rather than count - despite the differences in mereological properties among verb extensions (some verbs have an atomic extension, others don't). Thus conjoined verbs do not support plural anaphora, and numberrelated adverbial modifiers require a classifier (times in two times) (Moltmann 1997).

If this is right, then the mass-count distinction among nominalizations requires an account that does not draw on an ontological distinction among events or a distinction in mereological properties of extensions.

The action-product distinction raises a difficulty for the truthmaker-based semantics of event nominalizations. The difficulty is that actions and their products qualify equally, it seems, for the truthmaking of the very same sentences. But since they have such different properties, they should not both qualify as exact truthmakers of the same sentences. This is in 
fact part of the more general difficulty with considering events as truthmakers already mentioned earlier (Section 4).

\section{Events and states}

So far, this paper has set aside state nominalizations. That is because states, it has been argued, are not on a par ontologically with events. This relates to the observation that the states described by most stative verbs accept only a very restricted set of adverbial modifiers; they resist location modifiers, manner adverbials, instrumentals, and comitatives, and they cannot act as bare infinitival complements of perception verbs. The relevant stative verbs include own, know, resemble, weigh, measure, as well as copula be. Some researchers have taken this 'Stative Adverb Gap', as it is called, to mean that stative verbs lack a Davidsonian event argument position (Katz 2003); others have taken it to mean that states (at least as described by the relevant class of verbs) are ontologically rather different from events (Maienborn 2007). On Maienborn's view, states (described by verbs exhibiting the Stative Adverb Gap) are 'Kimian states' or 'abstract states' as I call them (Moltmann 2013b). That is, they are entities introduced by abstraction (Section 3). States so introduced are abstract in the sense that they will carry only properties specified for them by the method of introduction. Thus, on the Kimian account of states, states will have identity conditions and a temporal duration, but no other intrinsic properties? The Kimean account is given below, where $s$ is the function mapping an object $o$ and a property $P$ onto the state of $o$ having $P$ :

\section{(54) A Kimian account of states}

a. For a property $\mathrm{P}$, an object $\mathrm{o}$, the state $\mathrm{s}(\mathrm{o}, \mathrm{P})$ obtains at a time $\mathrm{t}$ iff $\mathrm{P}$ holds of $\mathrm{o}$ at $\mathrm{t}$.

b. For properties $\mathrm{P}$ and $\mathrm{P}^{\prime}$ and objects o and o', $\mathrm{s}(\mathrm{o}, \mathrm{P})=\mathrm{s}\left(\mathrm{o}^{\prime}, \mathrm{P}\right)$ iff $\mathrm{P}=\mathrm{P}^{\prime}$ and $\mathrm{o}=\mathrm{o}$.

The Kimian account of states in (54) still leaves two options open for the semantic analysis of state nominalizations. Based on (54), states could be introduced as referents of nominalizations of stative verbs in either of two ways: first, in terms of the Davidsonian account, by picking up states as the implicit arguments of stative verbs (albeit ontologically different from events) and second, in terms of the Kimian account, on the basis of the nominalization itself. In the first case, the semantics of state nominalization would be the same as that of event nominalizations. In the second case, the semantics of state 
nominalizations would be as below, where $N_{V}$ is the nominalization of the verb $V$ and $s$ again the function mapping an object and a property (namely the denotation of a verb) onto a state:

(55) $\left[\mathrm{N}_{\mathrm{V}}\right]=\{\mathrm{e} \mid \exists \mathrm{o}(\mathrm{e}=\mathrm{s}(\mathrm{o},[\mathrm{V}]))\}$

The truthmaker account is not applicable to abstract state nominalizations. Abstract states cannot act as truthmakers since abstract states are not entities in the world, but rather are on a par with non-worldly facts. They are not concrete in the sense of being fully specific and in space and time. Abstract states have a temporal duration only due to the method of their introduction.

Given the other two theoretical options, the Davidsonian and the Kimian account, it is then worth taking a closer look at actual nominalizations of stative verbs. First, stative verbs always have gerundive nominalizations. Gerundive nominalizations certainly stand for abstract states, as the resistance to relevant predicates, on the relevant reading, illustrates:

(56) a. ??? John's resembling Bill is striking / unusual.

b. ??? John knowing French is profound / superficial.

In addition, though, stative verbs may have other nominalizations, and those do not quite pattern the same. Thus there are differences in semantic behavior between resembling and resemblance as well as knowing and knowledge, as seen in the examples contrasting with (56a) and (56b) below:

(57) a. John's resemblance to Bill is striking / unusual.

b. John knowledge of French is profound / superficial.

Note that the same predicates in (56) and (57) can form adverbial modifiers of the verbs resemble and know. This means that those verbs should not take as Davidsonian arguments the very same abstract states as are described by their gerundive nominalizations:

(58) a. John resembles Bill in an unusual / striking way.

b. John knows French in a profound / superficial way. 
Yet resemble and know do not permit spatial adverbials (??? John resembles Mary in France, ??? John knows Mary in the house). This indicates that resemblance and knowledge describe tropes or trope-like entities. Tropes allow predicates that concern the ways the property in question is manifested (manner predicates), which abstract states do not. Yet tropes by nature do not in general allow for spatial modifiers (Moltmann 2013b):

(59) a. ??? John's wisdom / nervousness / happiness was in France.

b. ??? the cake's deliciousness on the table

Abstract states and tropes also differ with respect to their part structure and their measurability. Abstract states, like facts, cannot have parts nor can they be measured, but tropes can, as is reflected in the data below:

(60) a. ??? part of John's being wise / nervous / intelligent

b. part of John's wisdom / nervousness / intelligence

(61) a. ??? There is more being wise in this book.

b. There is more wisdom in this book.

The same pattern can be observed for the two nominalizations of stative verbs of the relevant sort:

(62) a. Part of John and Bill's resemblance is due to their genes.

b. ??? Part of John and Bill's resembling each other is due to their genes.

(63) a. Part of John's knowledge of French is due to his year as an exchange student.

b. ??? Part of John's knowing French is due to his year as an exchange student.

(64) a. There is more resemblance to Bill than resemblance to Mary.

b. ??? There is more resembling Bill than resembling Mary.

The semantic behavior of the two sorts of nominalizations, gerunds vs nominalizations of the sort resemblance and knowledge, suggests that at least certain stative verbs that do not permit spatial adverbials have two distinct nominalizations: first gerundive nominalizations for abstract states and second non-gerundive nominalizations for entities that are tropes (e.g. relational tropes of resemblance) or closely related to tropes (e.g. knowledge). This means that a gerund may refer to an abstract state even if the implicit Davidsonian argument of the 
verb is not an abstract state but rather a trope or trope-like entity. ${ }^{12}$ In such a case, then, a Kimian semantics of gerundive nominalization will be the only option, that is, a semantics according to which the gerund introduces an abstract state, by abstraction from the content of the verb.

\section{Conclusion}

We have seen that despite its initial plausibility the Davidsonian account of event nominalisations and adverbial constructions faces serious challenges, most importantly from the possibility of stacked adverbials, from interactions of adverbials and quantifiers and from the corresponding nominal constructions. Those constructions do not involve entities already acting as implicit arguments, but, it seems, introduce them themselves. There is a view according to which this holds even for simple event nominalizations and adverbial constructions, namely the view that events come to play a role in the semantic structure of sentences only in virtue of those constructions and are not already present as implicit arguments of all verbs

However, the most well-known alternative to the Davidsonian account, the Kimean account of event nominalizations, is affected with serious difficulties regarding the ontology of events and its applicability to actual nominalizations in natural language. Yet that account appears to have one plausible application, namely to gerundive nominalizations of certain stative verbs such as resemble and know.

The third alternative, the truthmaking account, fares much better with respect to complex adverbial constructions and corresponding nominalizations. But it has to meet its own challenges regarding abstract state verbs as well as the notion of exact truthmaking in general. Nominalizations moreover require a more complex semantics in view of the action-product distinction among psychological and illocutionary verbs.

\section{References}

Armstrong, D. (1978): Universals and Scientific Realism, Vol. 1 and 2, Cambridge UP, Cambridge.

\footnotetext{
${ }^{12}$ Maienborn (this volume) furthermore argues that gerunds (infintival nominalizations in German) may refer to concrete states as entities distinct from tropes, namely when derived from verbs like sleep, sit, and glow.
} 
(1997): A World of States of Affairs. Cambridge UP, Cambridge.

(2004): Truth and Truthmakers. Cambridge UP, Cambridge.

Asher, N. (1993): Reference to Abstract Objects in Discourse. Kluwer, Dordrecht.

Austin, J. L. (1979): 'Unfair to Facts'. Philosophical Papers. Oxford University Press, New York.

Beebee, H. / J. Dodd (eds.) (2005): Truthmakers: The Contemporary Debate, Oxford University Press, 2005

Bennett, J. (1988): Events and their Names. Clarendon Press, Oxford.

Campbell, K. (1990): Abstract Particulars. Blackwell, Oxford.

Chisholm, R. (1970): 'Events and Propositions'. Nous 4, 15-24.

Chierchia, G. (1984): Topics in the Syntax and Semantics of Infinitivals and Gerunds. $\mathrm{Ph} \mathrm{D}$ dissertation, University of Massachusetts, Amherst.

Cresswell, M. (1985): Adverbial Modification. Kluwer, Dordrecht.

Davidson, D. (1967): 'The logical form of action sentences'. In N. Rescher (ed.): The Logic of Decision and Action. Pittsburgh University Press, Pittsburgh, 81-95. Reprinted in D.

Davidson: Essays on Actions and Events.

(1969). 'The individuation of events'. In N. Rescher (ed.): Essays in

Honour of Carl Hempel. Dordrecht: Reidel.

Dummett, M. (1973): Frege: Philosophy of Language. Duckworth, London.

Fine, K. (2012): ‘Counterfactuals without Possible Worlds'. Journal of Philosophy 109

(3), 221-246

- (2014): 'Truth-Maker Semantics for Intuitionistic Logic'. Journal of Philosophical

Logic 43, 2-3, pp 549-577

(to appear): 'Truthmaker Semantics'. Blackwell Philosophy of Language Handbook.

Frege, G. (1884): Die Grundlagen der Arithmetik: eine logisch-mathematische

Untersuchung uber den Begriff der Zahl. Translated by J. L. Austin as

The Foundations of Arithmetic. Blackwell, 1950.

(1892): 'Ueber Begriff und Gegenstand'. Vierteljahreszeitschrift fuer

wissenschaftliche Philosophie. XVI, 192-205.

Hale, B. (1987): Abstract Objects. Blackwell, Oxford.

Higginbotham, J. (1985): 'On Semantics'. Linguistic Inquiry 16.

(2000): 'On Events in Linguistic Semantics'. In Higginbotham et al. (2000):

Speaking of Events. Oxford UP, Oxford.

Katz, G. (2003): 'Events as Aguments, Adverb Selection, and the Stative Adverb Gap'. In E. 
Lang eds. (eds.): Modifying Adjuncts, de Gruyter.

Kim, J. (1976): 'Events as property exemplifications'. In M. Brand / D. Walton (eds.): Action Theory. Dordrecht: Reidel.

Landman, F. (2000): Events and Plurality. Kluwer, Dordrecht.

Laurence, S. / C. Macdonald (eds.) (1998): Contemporary Readings in the Foundations of Metaphysics. Blackwell, Oxford.

Lewis, D. (1983): 'New work for a theory of universals'. Australasian Journal of

Philosophy 61/4, 343-377. Reprinted in Mellor/Oliver (eds.), 188-227. (2001): 'Truthmaking and Difference-Making'. Nous 35, 602-615.

Lombard, L. B. (1986.): Events. A Metaphysical Study. London: Routledge / Kegan.

Lowe, J. (2006): The Four-Category Ontology. A Metaphysics Foundation for Natural Science. Oxford UP.

Maienborn, C. (2007): 'On Davidsonian and Kimian states'. In: I. Comorovski \& K. von

Heusinger (eds.). Existence: Semantics and Syntax. Dordrecht: Springer, 107-130.

(to appear): 'Events and States'. This volume.

Montague, R. (1960): 'On the Nature of Certain Philosophical Entities'. Monist 53, pp.

159-194, reprinted in R. Montague: Formal Philosophy, Yale UP, New Haven, 1974.

Moltmann, F. (1997): Parts and Wholes in Semantics. Oxford: Oxford UP.

(2007): 'Events, Tropes and Truthmaking'. Philosophical Studies 134, 2007, 363-403.

(2009): 'Degree Structure as Trope Structure A Trope-Based Analysis of

Comparative and Positive Adjectives'. Linguistics and Philosophy 32, pp. 51-94. (2013a): Abstract Objects and the Semantics of Natural Language. Oxford:

Oxford UP.

(2013b): 'On the Distinction between Abstract States, Concrete States, and

Tropes'. A. Mari / C. Beyssade / F. Del Prete (eds.): Genericity, edited by, Oxford UP,

Oxford, 2013, pp. 292-311.

(2014): 'Propositions, Attitudinal Objects, and the Distinction between

Actions and Products'. Canadian Journal of Philosophy 43 (5-6), special issue

on propositions, edited by G. Rattan and D. Hunter, 679-701.

-- (2015): ‘States vs Tropes. Commentary on Marcyn Morzicki: 'Degrees as Kinds

of States'. Natural Language and Linguistic Theory 33. 3, Special issue edited by B.

Gehrke and E. Castroviejo Miró, pp. 829-841. 
(to appear a): Cognitive Products and the Semantics of Attitude Verbs and

Deontic Modals'. In F. Moltmann / M. Textor (eds.): Act-Based Conceptions of

Propositional Content. Contemporary and Historical Perspectives. Oxford UP.

(to appear b): 'On the Ontology of Cases'. To appear in De la passion du sens en

linguistique: hommages à Danièle Van de Velde, edited by N. Flaux, P. Haas, K. Paykin,

V. Mostrov et F. Tayalati., 2015, Les Presses Universitaires de Valenciennes. (ms) : 'A Truthmaker Semantics for Cases'. Ms NYU.

Mulligan, K. / P. Simons / B. Smith (1984): 'Truth Makers'. Philosophy and

Phenomenological Research 44, 287-321.

Parsons, T. (1990): Events in the Semantics of English. MIT Press, Cambridge (Mass.).

Peterson, P. (1997): Fact, Proposition, Event. Kluwer, Dordrecht.

Reichenbach, H. (1947): Elements of Symbolic Logic. Toronto: Macmillan.

Restall, G. (1996): 'Truthmakers, Entailment, and Necessity'. Australasian Journal of Philosophy 74, pp. 331-340.

Rodriguez-Pereyra, G. (2005): 'Why Truthmakers'. In Beebee/Dodd (eds.).

Russell, B. (1918/9): ‘The philosophy of logical atomism'. The Monist 28 (1918), 495-527, 29 (1919), 190-222, 345-80.

Schiffer, S. (1996): 'Language-created and Language-independent entities'. Philosophical

Topics 24.1., 149-167.

(2003): The Things we Mean. Oxford: Clarendon Press.

Sharvy, R. (1981): 'A more general theory of descriptions'. Philosophical Review 89, 607-624.

Strawson, P. (1950): 'Truth', Proceedings of the Aristotelian Society, reprinted in Strawson 1971, Logico-Linguistic Papers, Methuen, London, 1971.

Taylor, B. (1985): Modes of Occurrences. Blackwell, New York.

Twardowski, K. (1911): 'Actions and Products. Some Remarks on the Borderline of Psychology, Grammar, and Logic'. In J. Brand1/J. Wolenski (eds.): Kazimierz

Twardowski. On Actions, Products, and Other Topics in the Philosophy. Rodopi, Amsterdam and Atlanta, 1999, 103-132.

Vendler, Z. (1967). Linguistics in Philosophy. Cornell University Press, Ithaca, NY.

Williams, D. C. (1953): 'On the elements of being'. Review of Metaphysics 7, 3-18.

Reprinted in Mellor/Oliver (eds.), 112-124.

Woltersdorff, N. (1960): 'Qualities'. Philosophical Review 69. Reprinted in A.

Schoedinger (ed.): The Problem of Universals. Humanities Press, New Jersey, 1992. 
(1970): On Universals. Chicago UP, Chicago.

Wright, C. (1983): Frege's Conception of Numbers as Objects. Aberdeen UP, Aberdeen. 